\title{
COMPOSIÇÃO GRAVIMÉTRICA DOS RESÍDUOS SÓLIDOS URBANOS DA COLETA CONVENCIONAL DE UM MUNICÍPIO DE PEQUENO PORTE
}

\author{
*Silvana De Jesus Galdino ${ }^{1}$, Carlos Humberto Martins ${ }^{2}$ \\ ${ }^{I}$ Geógrafa, Mestre em Engenharia Urbana/Universidade Estadual de Maringá-UEM-PR \\ ${ }^{2}$ Professor, doutor. Departamento de Engenharia Civil/Universidade Estadual de Maringá-UEM-PR \\ *E-mail: silgaldino@outlook.com
}

Recebido em: 19/05/2015

Aceito em: 04/08/2015

\section{RESUMO}

O Brasil gera aproximadamente 209. 280 t/dia de resíduos sólidos urbanos, 189.219 t/dia são coletadas, ou seja, 20.000 t/dia deixam de ser coletadas, sendo encaminhadas para locais inadequados. Diante do contexto, a pesquisa teve por finalidade, a caracterização física dos resíduos sólidos domiciliares do município de Mamborê-PR, visando contribuir com informações relacionadas à quantidade de resíduos potencialmente recicláveis encaminhados ao aterro e para a elaboração do Plano de Gerenciamento Integrado de Resíduos Sólidos (PGIRS). A caracterização física dos resíduos sólidos foi realizada através do método de quarteamento, o qual consiste na segregação minuciosa das amostras, e posterior pesagem individual para verificar a porcentagem em peso dos resíduos. A segregação e pesagem dos resíduos contaram com a participação dos catadores de materiais recicláveis, como forma de envolver esses trabalhadores em ações de incentivo a coleta seletiva. Observou-se a predominância da fração orgânica nas análises, ou seja, 54\% do total coletado, uma das características das localidades de pequeno porte, seguido de 38,6\% de materiais recicláveis, $5,4 \%$ de rejeitos e $2 \%$ de outros tipos de resíduos. A caracterização física dos resíduos demonstrou ser importante para o desenvolvimento de projetos de coleta, transporte, tratamento, destinação final, até mesmo para a implantação de um centro de triagem e compostagem de resíduos sólidos (CTCRS) no município.

Palavras-chave: Resíduos sólidos. Coleta convencional. Caracterização física

\section{Introdução}

O crescimento da população urbana, juntamente com o consumismo exagerado, tem contribuído para a escassez dos recursos naturais, aumento da quantidade e diversidade de resíduos descartados diretamente na natureza, sem qualquer tipo de tratamento prévio.

Dados estatísticos [1] apontam que a geração de resíduos sólidos urbanos no Brasil é de 209.280 t/dia, com acréscimo de 4,1\%, de 2012 para 2013, índice superior à taxa de crescimento populacional urbano no país no período, que foi de 3,7\%. Dentre a taxa total de RSU gerada, foram coletadas $189.219 \mathrm{t} / \mathrm{dia}$, entretanto, 20.000 t/dia deixaram de ser coletadas no Brasil sendo destinadas de maneira imprópria.

Informações disponibilizadas [2] apontam que, 32,3\% dos municípios brasileiros têm um programa, projeto ou ação de coleta seletiva de lixo em atividade. Todavia, em 42,7\% das cidades não há nenhuma iniciativa, em $2,5 \%$ das cidades, a coleta chegou a existir e está interrompida. Há projeto em fase de desenvolvimento em 19,2\% das administrações municipais, e em $3,3 \%$, um projeto piloto começou a ser aplicado em área restrita [2].
Atualmente, uma das grandes preocupações da administração pública municipal, no Brasil, constitui a questão do planejamento do serviço de coleta, da definição das formas de tratamento e da disposição final dos resíduos sólidos gerados pela população urbana [3]. Desta forma, realizar um levantamento das características dos resíduos sólidos urbanos é fundamental para definir formas de disposição final mais adequada, implantação de sistemas de tratamento e de coleta seletiva [4].

$\mathrm{O}$ aumento da quantidade e diversidade de resíduos descartados de maneira inadequada também está relacionado às mudanças nos padrões de consumo das sociedades, fatores culturais, socioeconômicos e políticos [5]. Estes fatores quando não trabalhados de forma integrada dificilmente geram resultados significativos.

Com base em estudos realizados [6], o crescimento econômico e demográfico das cidades contribuiu para o aumento da produção de resíduos, que aliado à escassez de investimentos e à falta de compreensão sobre a diversidade de fatores que afetam as diferentes etapas, constitui como uma barreira à gestão integrada.

Diante deste contexto, as características dos resíduos sólidos podem variar em decorrências dos diferentes aspectos 
econômicos, culturais, geográficos e climáticos [7]. A composição tanto do ponto de vista quantitativo como qualitativo é considerado um dos dados básicos para o devido equacionamento da coleta, transporte e destinação final dos resíduos.

Para correta análise dos resíduos sólidos e posterior definição do melhor programa de gestão e gerenciamento, tornase necessário conhecer as características quantitativas e qualitativas dos mesmos [7]. Os resíduos sólidos urbanos podem ser classificados de acordo com: umidade (seco e molhado); aspecto econômico; resíduos reaproveitáveis; resíduos para a produção de compostos (resíduos orgânicos em geral); resíduos recuperáveis; e resíduos inaproveitáveis (inorgânicos em geral). Também podem ser classificados em: facilmente degradáveis (matéria orgânica putrescível, como restos de comida); moderadamente degradáveis (papelão e outros materiais celulósicos); dificilmente degradáveis (trapos, couro, borracha e madeira); e não degradáveis como vidros, plásticos e metais, entre outros [7].

A determinação da composição gravimétrica é um dos dados essenciais [8]. No caso dos resíduos de origem domiciliar e comercial, normalmente dispostos em aterro, os componentes discriminados na composição gravimétrica são: matéria orgânica putrescível, metais ferrosos, metais não ferrosos, papel, papelão, plásticos, trapos, vidro, borracha, couro, madeira, entre outros.

Há varias formas de realizar a composição gravimétrica dos resíduos, entretanto, a mais utilizada é o método de quarteamento da amostra [9].

Caracterizar os diferentes tipos de materiais que são encontrados nos resíduos das residências é importante para definir formas de disposição final mais adequada para a implantação de sistemas de tratamento para estes resíduos e para subsidiar sistemas de coleta seletiva. Saber quanto se produz permite dimensionar a frota, o tipo de veículo coletor e o número de funcionários para o serviço de coleta.

Desta forma, realizar o levantamentos dos resíduos sólidos provenientes da coleta convencional do município de MamborêPR, através da caracterização física, torna-se importante contribuição para o gerenciamento dos RSU.

\section{Metodologia}

\section{1 Área de Estudo}

Esta pesquisa foi realizada no município de Mamborê, localizado na Mesorregião Centro-Ocidental Paranaense, a 481 quilômetros de distância da capital do estado [10]. O município faz parte da Microrregião Homogênea 286 e pertence à COMCAM - Comunidade dos Municípios da Região de Campo Mourão, limitando-se com Campo Mourão e Farol ao norte, com Boa Esperança e Juranda a oeste, com Campina da Lagoa e Nova Cantú ao sul e com Luiziana a leste (Figura 1).

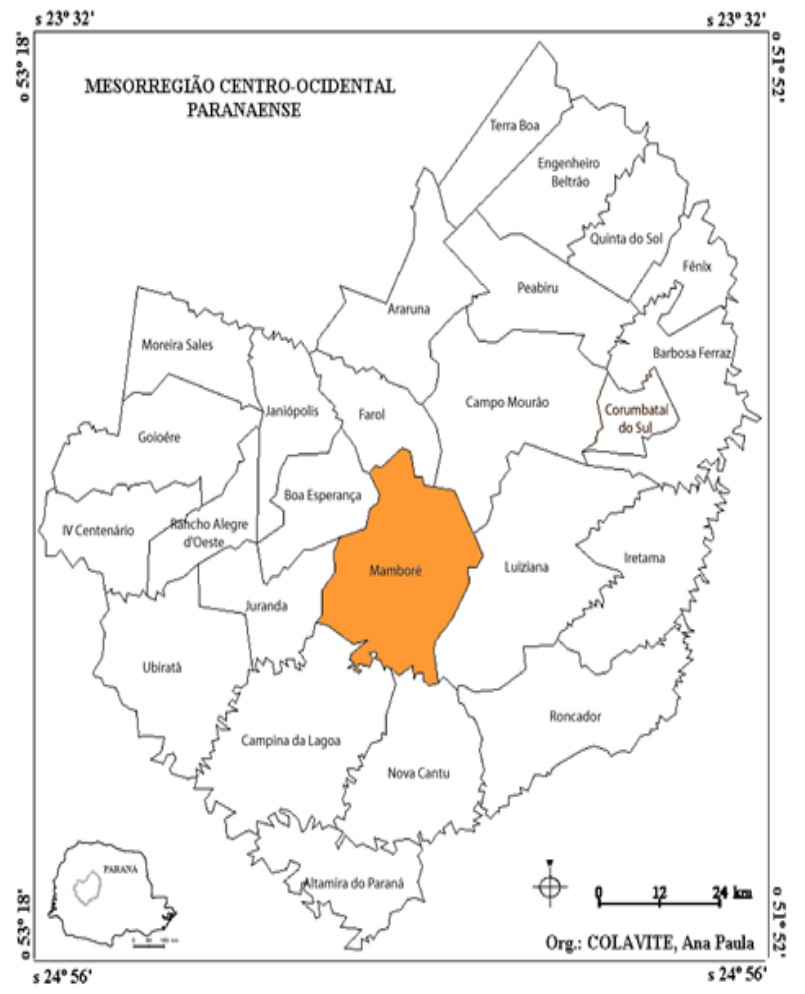

Figura 1: Mamborê-PR no contexto da Messoregião CentroOcidental Paranaense

Fonte: Adaptado de IPARDES [10].

O município de Mamborê ocupa aproximadamente $788,062 \mathrm{~km}^{2}$ de área no terceiro planalto paranaense, entre as

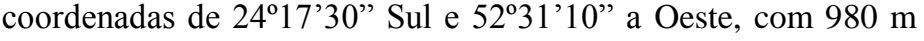
de altitude. O clima do município é do tipo cfa ou subtropical úmido, sendo a média pluviométrica anual de $1.500 \mathrm{~mm}$ e média de temperatura de $20^{\circ} \mathrm{C}$ [11]. Possui uma população de 13.961 habitantes, destes 8.984 residem na área urbana, de acordo com o Instituto Brasileiro de Geografia e Estatística [11]

\subsection{Procedimentos}

A composição gravimétrica dos resíduos sólidos provenientes da coleta convencional do município de MamborêPR foi realizada no mês de junho de 2014, em local disponibilizado pela Secretaria de Agricultura e Meio Ambiente, considerando 3 amostras, de forma a abranger todas as áreas do perímetro urbano. O levantamento contou com a colaboração e participação de membros do setor e catadores de materiais recicláveis da associação do município.

Nesta etapa de coleta de dados, foi realizada a caracterização física dos resíduos sólidos destinados ao aterro controlado do município de acordo com o método de 
quarteamento em conformidade com as orientações propostas [9$12]$.

Este método envolve a escolha dos critérios de representatividade, descarga dos resíduos em local adequado (impermeabilizado), rompimento dos sacos e revolvimento e homogeneização da pilha de resíduos. Após adotar estes critérios, procede a coleta de quatro amostras, sendo uma no topo e três na base, de modo a encher quatro tonéis de 200 litros cada, totalizando 800 litros. Ambas as amostras foram minuciosamente segregadas e pesadas para obter a porcentagem de cada tipo de resíduo presente na coleta convencional.

Por meio da caracterização física das amostras selecionadas, foi possível estipular a porcentagem de cada material encontrado nos resíduos sólidos urbanos destinados ao aterro controlado.

As porcentagens foram obtidas levando em consideração a separação dos resíduos de acordo com a classificação proposta pela Associação Brasileira de Normas Técnicas (ABNT), NBR 10.004/2004 e NBR n 13.230/2008 [9-13], as quais estabelecem a numeração dos plásticos em 6 diferentes tipos: PET-Polietileno Tereftalato; PEAD-Polietileno de Alta Densidade; PVCPolicloreto de Vinila; PEBD-Polietileno de Baixa Densidade; PPPolipropileno; PS-Poliestireno, e incluindo uma sétima opção, outros. As simbologias têm como objetivo, identificar cada material de embalagem, facilitando o encaminhamento para programas de reciclagem.

\subsection{Recebimento da Coleta e Homogeneização}

Primeiramente, procedeu-se a escolha das coletas a serem consideradas para análise e em seguida a impermeabilização do solo para receber a coleta. Após, o caminhão da coleta convencional descarregou os resíduos sob duas lonas pretas de aproximadamente $48 \mathrm{~m}^{2}$, formando-se pilhas de resíduos (Figura 2).

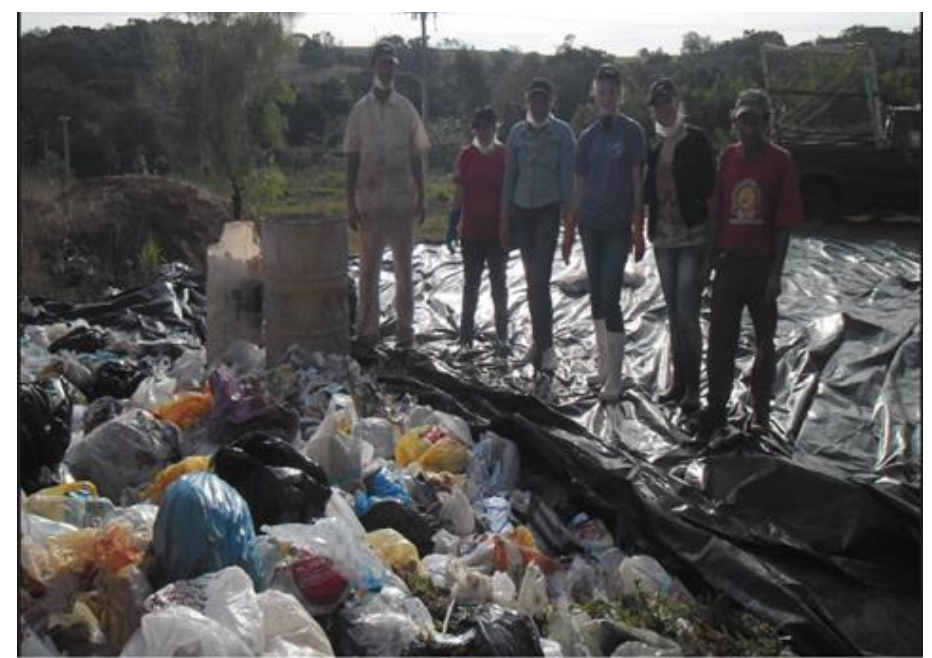

Figura 2: Recebimento e homogeneização das amostras de RSU
Em seguida, os invólucros contendo os resíduos foram todos rompidos para proceder à homogeneização da amostra, esta que exigiu a utilização de pás e enxadas para facilitar o processo manual. Após a homogeneização do total da pilha de resíduos, realizou-se a coleta de 4 tambores de 200 litros, sendo 3 na base e 1 no topo, totalizando 800 litros, os quais, posteriormente foram minuciosamente segregados conforme determina [9].

\subsection{Segregação e Pesagem das Amostras}

$\mathrm{Na}$ Figura 3, observa-se os recipientes que foram utilizados para acondicionar as amostras utilizadas para análise e balança para pesagem. Estes foram devidamente pesados quando vazios e também cheios para obter-se a tara e verificar o peso dos materiais antes da segregação.

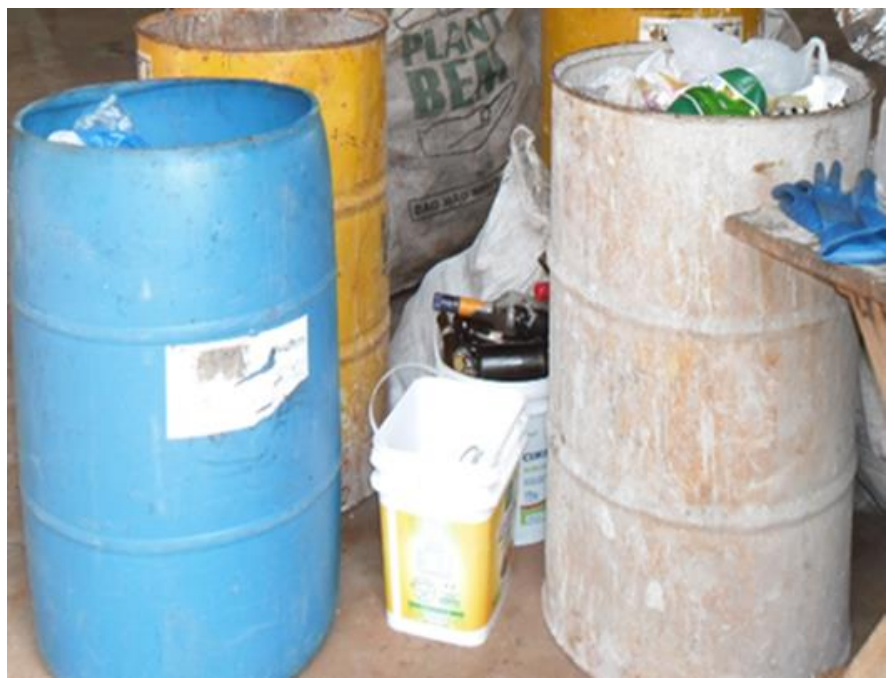

Figura 3: Recipientes utilizados para armazenar as amostras

Após obter o peso total dos resíduos, estes foram dispostos em lona preta para posterior segregação e pesagem individual dos mesmos. As parcelas separadas foram armazenadas em sacos de lixo pretos de 50, 100 e 150 litros, os quais foram pesados para obter a porcentagem em peso (Figura 4). 


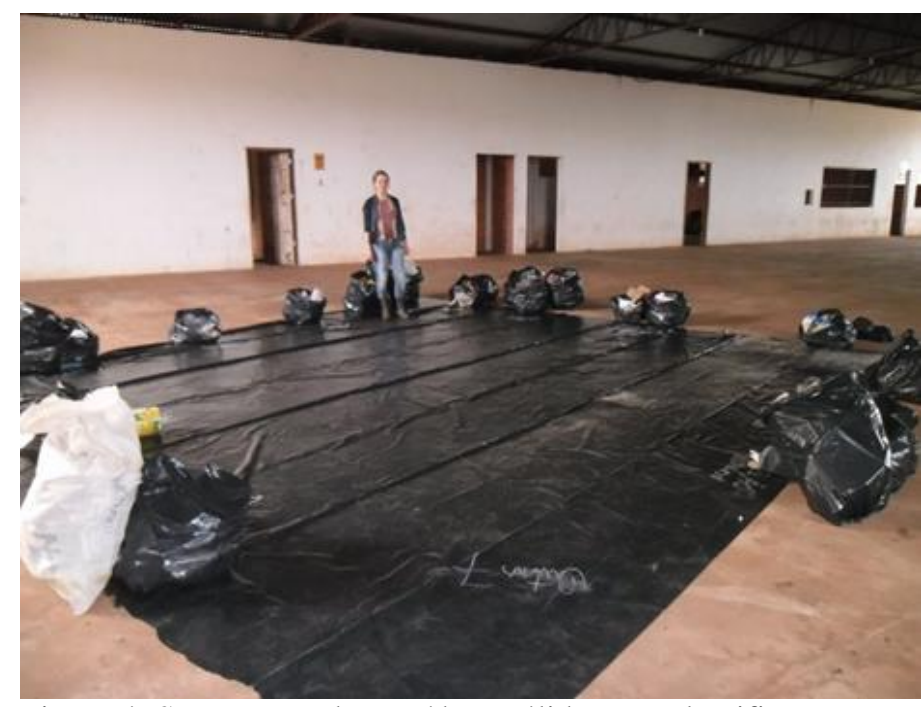

Figura 4: Segregação dos resíduos sólidos por classificação

\section{Resultados e discussões}

\subsection{Coleta Convencional}

O órgão responsável pela gestão dos resíduos sólidos é a Prefeitura Municipal de Mamborê-PR, setor de Agricultura e Meio Ambiente, com 8.925 habitantes atendidos, incluindo distrito sede e localidades.

De acordo com dados do Sistema Nacional de Informação sobre Saneamento [14], o percentual da população urbana atendida com frequência diária de coleta em Mamborê é $10 \%$, frequência de 2 a 3 vezes por semana é de $80 \%$, frequência de 1 vez por semana é $10 \%$.

A Secretaria de Agricultura e Meio Ambiente destaca que, para manejo dos resíduos sólidos domiciliares e de limpeza pública, são utilizados 2 caminhões compactadores, 6 caminhões basculantes, baú ou carroceria, 1 caminhão poliguindaste, 2 tratores agrícola com reboque e 1 pá carregadeira e 1 escavadeira utilizada na manutenção do aterro.

A coleta dos resíduos sólidos domiciliares da área urbana do município é realizada com caminhão compactador (Figura 5) e trator com caçamba. Ambas as coletas são realizadas durante o dia, de segunda a sábado, das $7 \mathrm{~h}$ às $18 \mathrm{~h}$ e encaminhas ao aterro controlado, situado a $4 \mathrm{~km}$ da área urbana.

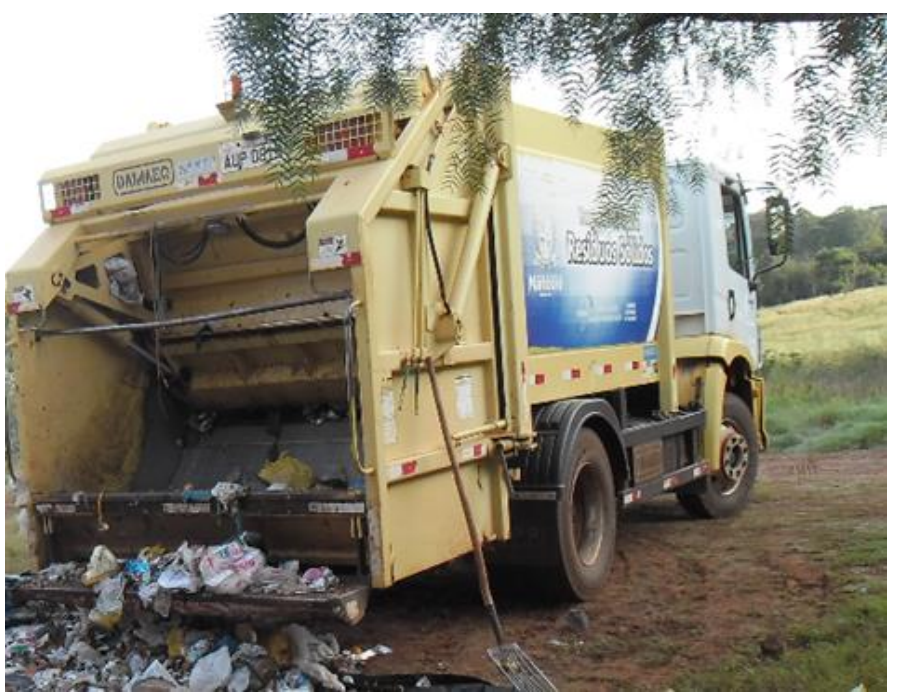

Figura 5: Veículo utilizado na coleta dos resíduos domiciliares

A cobrança pelo serviço de manejo dos resíduos sólidos urbanos, tais como coleta regular, transporte e destinação final é realizada pela Prefeitura em taxa especifica no mesmo boleto do Imposto Predial Territorial Urbano (IPTU), sendo a receita orçada com a cobrança de taxas e tarifas referentes à gestão e manejo de RSU em torno de $\mathrm{R} \$ 96.871,00$ por ano.

A quantidade de resíduos sólidos coletados no município é de $11.671 \mathrm{~kg} / \mathrm{dia}$, portanto, a geração per capita de resíduos sólidos do município de Mamborê é de aproximadamente 0,835 $\mathrm{kg} / \mathrm{hab} / \mathrm{dia}$ [15]. Considerando a população de 13.961 habitantes [15], a geração per capta por hab/dia do município de Mamborê está acima da média da geração per capita para os municípios entre 10.000 a 19.000 mil habitantes, que é de $0,420 \mathrm{~kg} / \mathrm{hab} / \mathrm{dia}$.

$\mathrm{O}$ percentual de domicílios atendidos segundo forma de coleta no meio urbano chega a $99,34 \%$ diretamente por serviços de limpeza, $12,32 \%$ em caçambas de serviços de limpeza e $0,66 \%$ coletados de outras maneiras [15].

Os resíduos gerados no município de Mamborê-Pr são predominantemente residenciais, sendo que os gerados nos comércios e nas indústrias são em menor fração. Em 100\% dos principais geradores há a presença de resíduos potencialmente recicláveis [15].

\subsection{Porcentagens Obtidas com a Classificação dos RSU}

A composição gravimétrica dos resíduos sólidos realizada no mês de junho de 2014 apresentou os seguintes resultados, que são apresentados na Figura 6. 


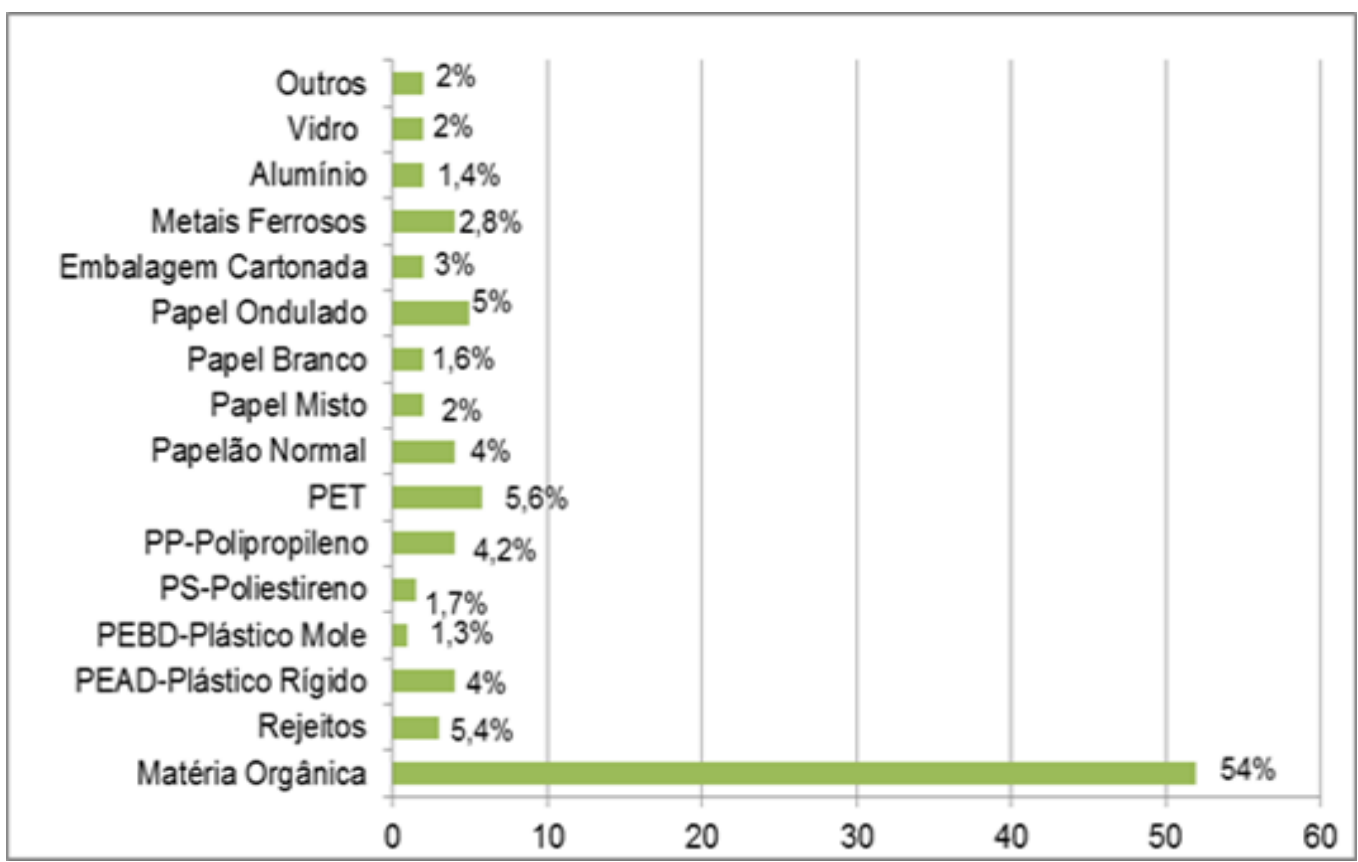

Figura 6: Gráfico da composição gravimétrica dos resíduos sólidos urbano (RSU) de Mamborê-PR

Os dados da Figura 6 permitem identificar o percentual de cada resíduo presente na amostra. Observa-se percentual significativo de matéria orgânica, com $54 \%$ do total da amostra, $8,6 \%$ de papel e $22,2 \%$ de plásticos, (PEAD, PEBD, PS, PP e PET). Os rejeitos, tais como fraldas, absorventes, papel higiênicos também foram significativos, com total de 5,4\% da amostra.

Através da caracterização dos resíduos, foi possível perceber um grande percentual de materiais recicláveis junto aos resíduos da coleta convencional, principalmente os plásticos rígidos de alta densidade, com 4\% PEAD e PET com 5,6\% do total. Tais resultados apontam para a necessidade de investimentos mais significativos em programas de educação ambiental junto à população, de maneira a conscientizar quanto à importância de separar os materiais recicláveis para a coleta seletiva, evitando que os mesmos sejam coletados junto aos resíduos orgânicos e rejeitos e, consequentemente, encaminhados ao aterro.

Os materiais recicláveis menos representativos encontrados nas amostras foram os metais ferrosos, com 2,8\% e alumínios, com $1,4 \%$ da amostra. Outro material pouco significativo, se comparado aos plásticos e papel, é o papelão com $4 \%$, fator atrelado à disponibilidade deste material em locais de fácil acesso para os catadores.

Com base na análise da composição gravimétrica foi possível identificar que $38,6 \%$ dos resíduos provenientes da coleta convencional são potencialmente recicláveis (Figura 7). Isso justifica a necessidade de uma maior valorização desses materiais e investimentos em coleta seletiva, devidamente organizada, com a valorização dos catadores.

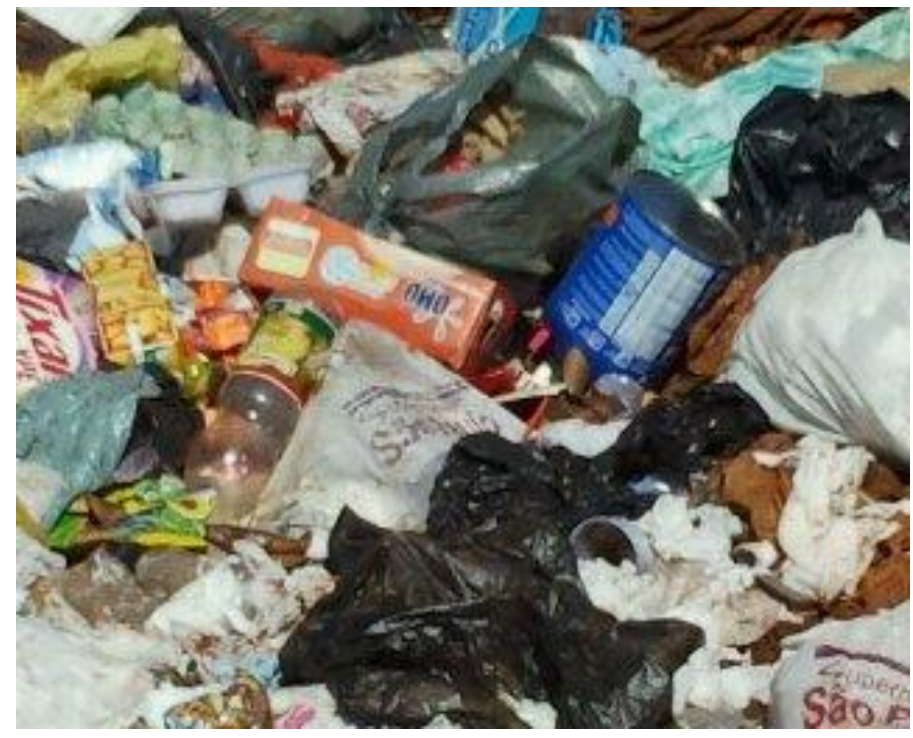

Figura 7: Diversidade de recicláveis na coleta convencional

Todos os materiais derivados do plástico, papel, papelão, vidro e multicamadas destacados na análise gravimétrica dos resíduos são passíveis de serem reciclados. Entretanto, de acordo com a Política Nacional de Resíduos Sólidos [16], existe exceção para os poliestirenos, lâmpadas, pilhas e baterias que necessitam 
de processo especial para a reciclagem e destinação final diferenciada.

De acordo com dados fornecidos pela Secretaria de Agricultura do município de Mamborê-PR, $60 \%$ do volume ocupado na trincheira do aterro são resíduos recicláveis coletados diariamente pela prefeitura. Portanto, há deficiências no sistema de coleta seletiva, ou seja, ela não ocorre de forma efetiva, fato que causa sérios impactos na vida útil do aterro (Figura 8), causando prejuízos ambientais, sociais e econômicos.

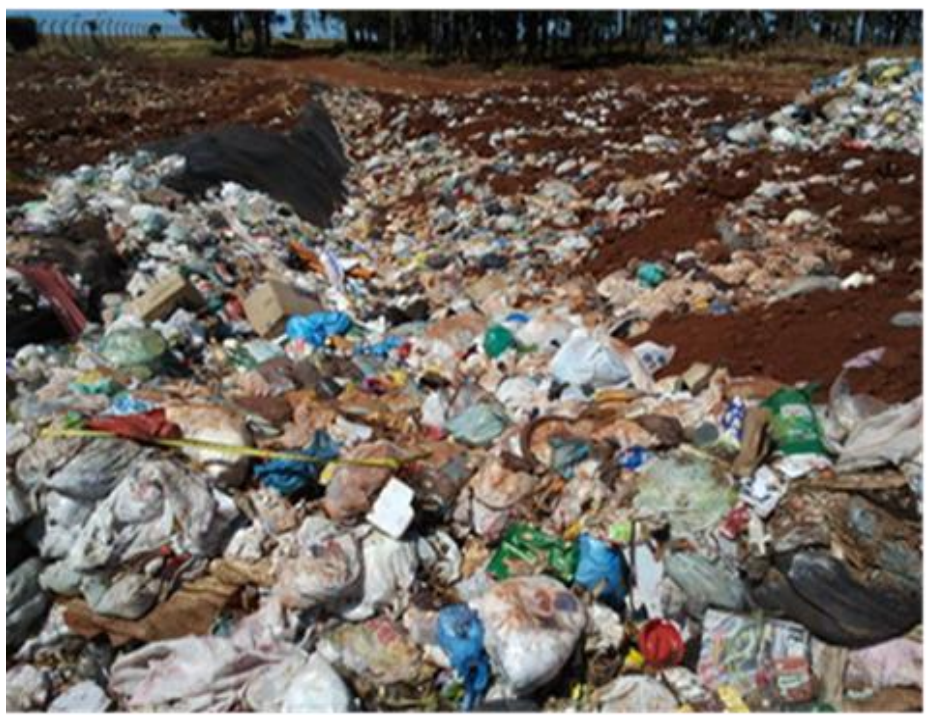

Figura 8: Presença significativa de materiais recicláveis no aterro

A destinação de materiais recicláveis no aterro dificulta o processo de compactação, atrai catadores que sobrevivem da comercialização desses materiais e dificulta a coleta, transporte e segregação desses materiais que se encontram misturados com matéria orgânica e rejeitos. Isso pode inviabilizar a comercialização, contaminar os materiais potencialmente recicláveis e expor o catador a riscos de saúde.

Os plásticos em aterros dificultam a compactação dos resíduos e prejudicam a decomposição dos materiais putrescíveis, pois criam camadas impermeáveis que afetam as trocas de líquido e gases gerados no processo de biodegradação da matéria orgânica [17].

A ausência de um sistema de compostagem de matéria orgânica justifica a grande quantidade desse material encontrado na composição dos resíduos e a necessidade da implantação de uma Central de Triagem e Compostagem de Resíduos Sólidos (CTCRS) no município. O composto, quando processado de maneira adequada, livre de contaminantes pode ser utilizado como adubo.

A compostagem no Brasil vem sendo tratada apenas sob a perspectiva de eliminar o lixo doméstico e não como um processo industrial que gera produto, necessitando de cuidados ambientais, ocupacionais, marketing, qualidade do produto, etc [7]. A parcela orgânica de RSU gerada no Brasil representa mais de $50 \%$ da composição, na maioria dos municípios, entretanto, a compostagem, como método de tratamento dos resíduos orgânicos, não é empregada como poderia, sendo compostados somente $1,5 \%$ dos RSU no país [18].

A coleta dos materiais recicláveis é realizada por catadores organizados em associação e autônomos que trabalham por conta própria. Todavia, a coleta não ocorre com a mesma intensidade em todas as épocas do ano, isso se deve às deficiências em equipamentos, infraestrutura e transporte dos materiais.

A associação não possui espaço adequado para triagem e armazenamento dos materiais. A coleta é realizada com carrinhos puxados a mão (Figura 9) e trator com carreta, ambos cedidos pela prefeitura do município, entretanto, este último não é disponibilizado diariamente, o qual é utilizado em outras atividades.

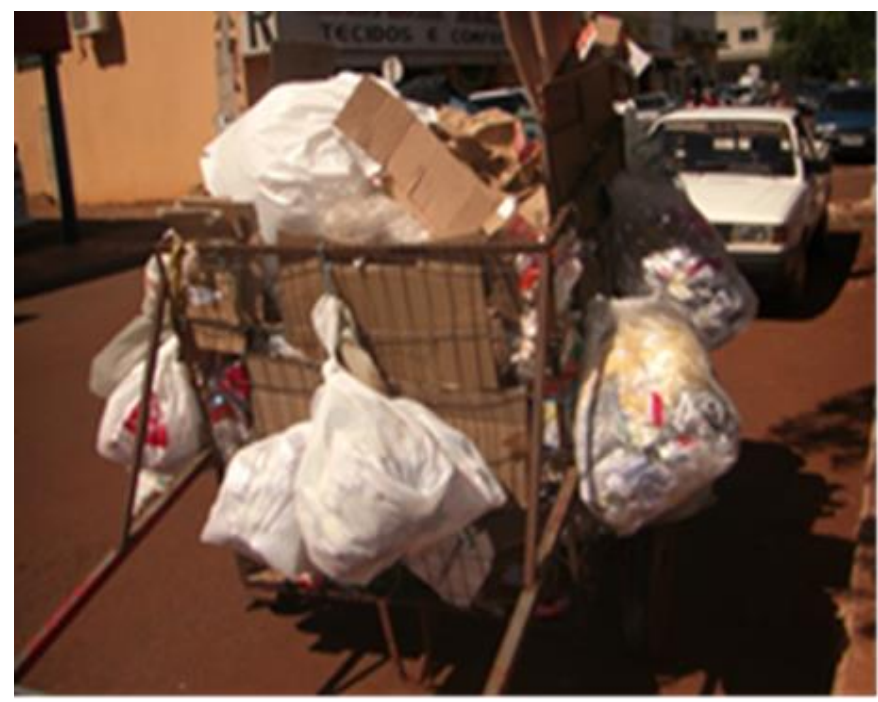

Figura 9: Transporte diário dos materiais recicláveis coletados

Os baixos investimentos em coleta seletiva também foram apontados como fator responsável pela presença significativa de materiais potencialmente recicláveis na composição gravimétrica.

\section{Considerações Finais}

Conforme constatado no município de Mamborê-PR, o gerenciamento dos resíduos sólidos urbanos não ocorre de maneira integrada, pois não há preocupação efetiva com o tratamento e disposição final. Isso poderia ser melhorado com campanhas de educação ambiental, sensibilização da população quanto à importância da segregação dos materiais diretamente na fonte geradora e o incentivo a coleta seletiva. 
Observou-se a predominância da fração orgânica nas análises, ou seja, 54\% do total coletado, uma das características das localidades de pequeno porte, seguido de $38,6 \%$ de materiais recicláveis, $5,4 \%$ de rejeitos e $2 \%$ de outros tipos de resíduos. A presença significativa de matéria orgânica e materiais potencialmente recicláveis justifica a necessidade de implantação de uma central de triagem e compostagem de resíduos sólidos no município.

Desta forma, a presente pesquisa vem contribuir na elaboração do plano de gerenciamento integrado dos resíduos sólidos, uma vez que, o município carece de dados referentes à caracterização física dos resíduos para o dimensionamento do processo de coleta, transporte, tratamento e destinação final dos resíduos. Os resultados encontrados podem contribuir para dimensionamento da frota, tipo de veículo a ser utilizado e quantidade de funcionários necessários para realizar a coleta.

A partir do conhecimento da caracterização física dos resíduos sólidos urbanos, mais especificamente a composição gravimétrica e geração total, é possível desenvolver, em conjunto com a educação ambiental voltada a população, um eficiente programa de gestão municipal de resíduos potencialmente recicláveis.

\section{Agradecimentos}

Agradecer a Coordenação de Aperfeiçoamento de Pessoal de Nível Superior (CAPES), a Fundação Araucária de Apoio ao Desenvolvimento Científico e Tecnológico do Paraná e o Programa de Pós-Graduação em Engenharia UrbanaPEU/UEM,PR/Brasil.

\section{GRAVIMETRIC COMPOSITION OF MUNICIPAL SOLID WASTE CONVENTIONAL COLLECTING OF A SMALL TOWN SIZE}

\begin{abstract}
Brazil generates about 209, 280 t/day of municipal solid waste, 189, 219 t / day are collected, and 20,000 t / day aren't collected, being conducted to inappropriate places. On the context, the research had the purpose, physical characterization of solid waste in the municipality of Mamborê-PR, to contribute with information related to amount of potentially recyclable waste going to landfill and for the development of the Integrated Plan of Solid Wastes Management (IPSWM). Physical characterization of solids residues was performed by quartering method, which constitutes thorough separation of the samples, and further individual weighing to verify the percentage by weight of wastes. Segregation and weighing the waste with the participation of collectors of recyclable materials as a way to engage these workers incentive stock selective collection. There was a predominance of the organic fraction in the analysis, being
\end{abstract}

$54 \%$ of the total collected was observed, a characteristic of small towns, followed by $38.6 \%$ of recyclable materials $5.4 \%$ and $2 \%$ of other types of residues. The physical characterization of waste proved to be important for the development of collection projects, transport, treatment, disposal, even the implementation of a sorting center and composting of solid waste (CTCRS) in the municipality.

Keywords: Solid waste. Conventional collection. physical characterization

\section{Referências}

[1] ABRELPE. Associação Brasileira de Empresas de Limpeza Pública e Resíduos Especiais. Panorama dos Resíduos Sólidos no Brasil. Ed 11 a 2013 . Disponível em: http://www.abrelpe.org.br/Panorama/panorama2013.pdf.Acesso em: 20 de Agosto de 2014.

[2] CEMPRE - Compromisso Empresarial para Reciclagem. Política Nacional de Resíduos Sólidos. 2012. Disponível em: http://www.cempre.org.br . Acesso em: 15 de Maio de 2015.

[3] LEME, S. M.; JÓIA, P. R. Caracterização física dos resíduos sólidos urbanos domiciliares em Aquidauana, MS. Geografia (Londrina) - v. 15, n. 1, jan./jun. 2006.

[4] FARIA, M. R. A.. Caracterização do resíduo sólido urbano de Leopoldina-MG: Proposta de implantação de um centro de triagem. Revista APS, v.8, n.2, p. 96-108, jul./dez. 2005.

[5] MARSHALL, E, R; FARAHBAKHSH,K. Systems Approaches to Integrated Solid Waste Management in Developing Countries. Waste Management.Vol. 33 (4), p. 9881003, 2013.

[6] GUERRERO, A, L; MAAS, G; HOGLAND, W. Solid Waste Management Challenges for Cities in Developing Countries. Waste Management. Vol.33 (1), p. 220-232, 2012.

[7] ANGELIS NETO, Generoso De. As deficiências nos instrumentos de gestão e os impactos ambientais causados por resíduos sólidos urbanos: o caso de Maringá/PR. 1999. 258 p. Tese (doutorado) - Escola Politécnica da Universidade de São Paulo. São Paulo, 1999.

[8] CASTIlhos. J, A. B.; LANGE, L. C.; GOMES, L. P.; PESSIN, N. Resíduos Sólidos Urbanos: aterro sustentável para municípios de pequeno porte. ABES, RiMa, Rio de Janeiro. Projeto PROSAB, 2003, 294p. 
[9] ABNT. Associação Brasileira de Normas Técnicas. NBR 10.004/2004 -Resíduos Sólidos - Classificação. $2^{\circ}$ ed. 71 p. São Paulo.

[10] IPARDES. Instituto Paranaense de Desenvolvimento Econômico e Social. Disponível em: http://www.ipardes.gov.br . Acesso em: 10 de Fevereiro de 2015.

[11] IBGE. Instituto Brasileiro de Geografia e Estatística. Estimativas Populacionais por município, 2010. Disponível em http://www.ibge.gov.br/ . Acesso: 10 de Janeiro de 2015.

[12] CONSONI, A. J.; SILVA, I. C.; GIMENEZ FILHO, A. Disposição final do lixo. In: D’ALMEIDA, M. L. O.; VILHENA, A. (Coord.). Lixo municipal: manual de gerenciamento integrado. 2. ed. São Paulo: Instituto de Pesquisas Tecnológicas IPT/ Compromisso Empresarial para Reciclagem - CEMPRE, 2000. cap. 5, p. 251-291.

[13] ABNT - Associação Brasileira de Normas Técnicas. NBR no 13.230. Embalagens e acondicionamento plásticos recicláveis - Identificação e simbologia, São Paulo, 2008.

[14] SNIS. Sistema Nacional de Informações sobre Saneamento. Ministérios das Cidades- Diagnóstico do Manejo de Resíduos Sólidos Urbanos, 2013. Disponível em:

http://www.snis.gov.br/PaginaCarrega.php?EWRErterterTERTer =16: Acesso em: 02 de Julho de 2015.

[15] SEMAM. Secretaria Municipal da Agricultura e Meio Ambiente. Plano Municipal de Gerenciamento de Resíduos Sólidos Urbano. Prefeitura Municipal de Mamborê-PR, 2014.

[16] PNRS. Lei Federal $n^{0} 12.305$ de 12 de Agosto de 2010. Política Nacional de Resíduos Sólidos. Brasília: MMA, 2010. Disponível em: http://www.camara.gov.br/sileg/integras/501911.pdf. Acesso em: 15 de Janeiro, 215.

[17] PINTO, A. G. Reciclagem de plástico. In: Lixo municipal: manual de gerenciamento integrado. São Paulo: Instituto de Pesquisas Tecnológicas (IPT) e Compromisso Empresarial para Reciclagem (CEMPRE), 2000. p.143-155.

[18] LAMANNA, S.R. Compostagem caseira como instrumento de educação ambiental e de minimização de resíduos sólidos. 2008. 192 p. Dissertação (Mestrado em Ciências Ambientais) Universidade de São Paulo, São Paulo, 2008. 